\title{
Agricultural cooperatives and the role of organisational models in new intelligent traceability systems and big data analysis
}

\author{
Cynthia Giagnocavo ${ }^{1 *}$, Fernando Bienvenido², Li Ming ${ }^{3}$, Zhao Yurong4, \\ J orge Antonio Sanchez-Molina², Yang Xinting ${ }^{3}$
}

(1.Cátedra (Chair) Coexphal-UAL of Horticulture, Cooperative Studies and Sustainable Development, University of Almeria, Spain; 2. Department of Informatics, University of Almeria, Almeria, Spain; 3. Beijing Research Center for Information Technology in Agriculture/National Engineering Research Center for Information Technology in Agriculture/National Engineering Laboratory for Agri-product Quality Traceability/Key Laboratory for Information Technologies in Agriculture, Ministry of Agriculture, China; 4. College of Economics and Management, Shandong Agricultural University, China)

\begin{abstract}
Traceability systems are key to assuring food safety, creating a benefit for food supply chain components. Currently, the appearance of new technologies such as IoT and Big Data Analysis leads to a new generation of more functional, but complex, traceability systems. Organisational models based on cooperation of multiple small/medium size agents, for example of small/family farming cooperatives, play an important role in high standard agricultural production and commercialization processes. These function as both social and economic networks, with high social and economic impact in the rural areas. The case of Almeria as an example of this model was used to analyze its cooperative model. The actual traceability systems in the Almeria model were studied, taking account of the different networked agents and their interrelation. This study includes two main parts: a) analysis of the net-chains that constitute the food supply chains and their different relationships, and b) actual traceability. The next step studied how the net-chain model, including many diverse agents, may be applied to develop a new generation of traceability systems based of IoT and Big Data. This implies extending the special and functional scope of the actual systems and defining clear rules of exchange of the results of the Big Data Analysis, taking account of the adequate Privacy Rules. This work analyses the current organisation as a base for a new generation of traceability systems considered in the European project IoF2020 (Internet of the Food and Farm 2020). Some parallels between Almeria's model and certain areas in China, mainly in the areas of Beijing-Tianjin-Hebei and Shandong were detected. Another of the objectives of this work is to deepen the understanding of these similarities and analyze the possible adaptation of the results from Almeria to China.
\end{abstract}

Keywords: food traceability system, big data, internet of things, organisational structure, business model, agricultural cooperatives, net-chains, food supply chain

DOI: $10.25165 /$ j.ijabe.20171005.3089

Citation: Giagnocavo C, Bienvenido F, Li M, Zhao Y R, Sanchez-Molina J A, Yang X T. Agricultural cooperatives and the role of organisational models in new intelligent traceability systems and big data analysis. Int J Agric \& Biol Eng, 2017; 10(5): 115-125.

\section{Introduction}

Designing and implementing effective food traceability systems is a complex process, which requires

\section{Received date: 2017-05-20 Accepted date: 2017-09-09}

Biographies: Fernando Bienvenido, PhD, Professor, research interests: vegetable traceability and modeling of agro-systems, Email: fbienve@ual.es; Li Ming, PhD, Associate Professor, research interests: warning system of greenhouse vegetable diseases, Email: lim@nercita.org.cn; Zhao Yurong, PhD, Associate Professor, research interests: theory and practice of rural finance, Email: zhaoyr9083@163.com; Jorge Antonio Sanchez-Molina, $\mathrm{PhD}$, Associate Professor, research interests: greenhouse climate and irrigation modelling and automatic control, an understanding of not only technical issues, but also business, organisational, economic, and social aspects. While much emphasis is often directed towards the

Email: jorgesanchez@ual.es; Yang Xinting, PhD, Professor, research interests: IOT for agri-product traceability, Email: yangxt@nercita.org.cn.

*Corresponding author: Cynthia Giagnocavo, $\mathrm{PhD}$, research interests: agricultural cooperatives, innovative ICT organisational and business models and social-economic sustainability. Cátedra (Chair) Coexphal-UAL of Horticulture, Cooperative Studies and Sustainable Development, University of Almeria, Spain. Email: cgiagnocavo@ual.es. 
technical innovations in ICT and traceability, organisational innovation and design should not be neglected in the analysis. The new generation of traceability systems based on the extensive use of Internet of Things and Big Data technologies in Smart Farming, as described by Wolfert et al. ${ }^{[1]}$, requires a holistic view including a model of organisation of networked global management. Such nuanced approach could aid in improved implementation and functioning of innovative traceability systems and technologies, ensuring that adequate organisational structures and business models are utilised. The focus on organisations arises from what Coase ${ }^{[2]}$ called "the institutional structure of production”. Most organisations are not based on pure market relationships, but have varying arrangements for control, coordination and incentives; that is, they have varying mechanisms which are efficient for dealing with knowledge based activities, diverse interests which need alignment and situations where information is not perfect. The "business model" of any given organisation refers to how it creates, delivers, and captures value, in economic, social, cultural or other contexts ${ }^{[3]}$. This paper will consider the role of cooperatives as innovative organisational structures and business models in traceability systems according to the problem of integration of traceability and smart farming ${ }^{[4]}$.

Innovation, with regard to businesses, refers to the "implementation of new or improved organisational methods in the firm's, business practices, human resources, workplace organisation or external relations”[5]. What is of note here is the mention of not only what happens inside the firm, but also the external relations. Innovation is not confined to the analysis of single firm and its relations, but also includes populations of firms and their economic and social “ecosystems”. Other wider interpretations of innovation point to any change (not just technological), based on knowledge (not just scientific), that generates value (not just for businesses) ${ }^{[6]}$. The inherent theme in these approaches to innovation is the process of adaptation and subsequent adoption of products, processes, services, systems, organisations, markets, techniques and business models; in essence, the process by which change is carried out and creates value.
Since innovation does not occur in a vacuum, the field of organisational design looks to the relationship between organisational structures and innovation. Processes of learning and organisational knowledge creation are also important elements. Organisations with different structures may vary in both learning and knowledge creation, resulting in different innovative capabilities ${ }^{[7]}$. Finally, the ability of a business, or ecosystems of firms, to adapt and adopt new forms, technologies or procedures, determines how changes or disruptions in technology or volatility in external conditions dealt with.

\section{Traceability in complex organisations as cooperatives}

Traceability has a key role in the added value chain of the agricultural products, improving it with the use the new accessible technologies, contributes to the sustainable development of the agricultural sector. Among the different models of production, one is based on cooperatives whose members are small/family farmers. In order to assure an adequate evolution of the current traceability systems to the next generation, it is necessary to take into account their organisational models. We must point out that there are different models of integration of the cooperatives and chain-supply agents that must be considered in order to assure the sustainability of a model that offers a social and economic stability, using as an example the case of Almeria’s agricultural cluster.

\subsection{Enhanced traceability as added value}

Enhanced traceability has increasingly become a method by which agricultural producers, businesses and actors add value to their production ${ }^{[8]}$. It is an integral part of logistics management in which traceability systems include both tracing and tracking of goods, services and related information ${ }^{[9]}$. Traceability can be considered with respect to not only the supply chain (integration of all functions that are involved in the sourcing of product and ends with the final customer) but also the value chain (inter-related activities and subsystems that focus on creating or adding value, in a broad sense of the word, to the product). In addition to food safety, growing concerns about consumer 
confidence, sustainable processes, environmental impacts and footprints, labour conditions, origin, food counterfeiting, quality, healthy eating, etc., have expanded the view of traceability beyond just the simple tracking of a product from point $\mathrm{A}$ to point $\mathrm{B}$, thus implicating both supply and value chains.

\subsection{Cooperatives organisations}

The question then, from an organisation design point of view, is "what agricultural organisations and business models may contribute to the adaption and adoption of traceability systems and related technologies, and subsequently, the addition of value?", "What organisational models or designs "fit" the activity, in this case, traceability systems?"

We consider that agricultural cooperatives have been found to be an efficient model in many regions. A 2013 extensive study, Support for Farmers' Cooperatives, led by the University of Wageningen, concluded that in all agriculturally advanced countries, agricultural cooperatives play a major role in almost all aspects of food production and marketing, enjoying an overall competitive market share of over more than $50 \%{ }^{[10]}$, with some sectors as high as $70 \%$. The cooperative business model can be a means to promote and contribute to organisational innovation, which in turns supports innovative traceability technology and processes. Both technical and organisational innovation go hand in hand as a competitive factor.

A study by the Rural Development Institute ${ }^{[11]}$ also found that cooperatives all over the world provide marketing and traceability supports to their members. Primarily, cooperatives carry out marketing related activities, both storing and selling farmers' production, all the while creating economies of scale and increasing bargaining power. At times, they are also involved in transport and processing. Cooperatives carried out other functions such as, conducting marketing surveys, streamlining quality control enforcement, inspection, and improvement in grading and standardization, organizing regulated markets' activities; prevention of unethical practices by members; enforcing standardization; and providing mechanisms for dispute resolution.

Turning to Spain, there are 3762 agricultural cooperatives, which account for $64 \%$ of the total value of agricultural production. In addition, they represent 30\% of turnover of the whole agri-food industry, even though cooperatives only makeup $13 \%$ of the companies. $33 \%$ of first level cooperatives (farmers are members) and $47 \%$ of second level cooperatives (cooperatives are members) export their product, suggesting high adoption levels of traceability and certification compliance, given the demanding European export market. 22\% of agricultural cooperatives are in Andalucía in southern Spain, which are responsible for $34 \%$ of the value of total agricultural production ${ }^{[12]}$.

\subsection{Almeria case}

Within Andalucía, we refer to the vegetable production of Almeria, illustrated in Figure 1, an area of almost $30000 \mathrm{hm}^{2}$ of mid-tech greenhouses, cultivated by more than 13500 smallholder farmers who are organised predominantly in 80 cooperatives for the marketing of their production. Each small white square, visible in Figure 1, is a small family farm greenhouse. Exportation by cooperatives in Almeria reaches levels of $75 \%$, suggesting high levels of compliance with traceability and certification standards. 96\% of exports are destined for the European Union, led by Germany, representing approximately $29 \%$. In the organisational design of Almeria, member farmers own and farm their land (approximately 2 ha.), and deliver it by small trucks to the cooperatives, which package and market the product. Companies transport the fresh produce to markets, usually by truck road transport to countries predominantly in the north and central Europe. There are over 398 export companies in Almeria, handling produce worth over 2.622 billion Euros for $2016^{[13]}$.

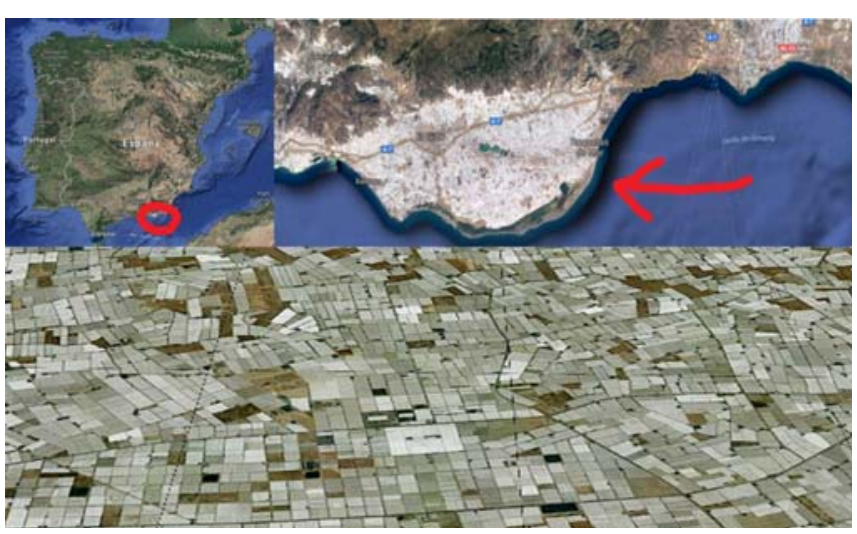

Figure 1 Almeria greenhouses 
In order to map the organisational design of Almeria's farmers, their cooperatives and their markets, we begin with the organisational nature of supply and value chain relationships. It is necessary to understand inter-organisational relationships, economic relations and market incentives coordination mechanisms in order to plan for innovation, efficient traceability and transfer of knowledge in agricultural systems. Thereafter, organisational design solutions to traceability challenges are set out.

Almeria's sector organisation is based on the family farm/owner and producer unit: predominantly farmers working two hectares with the help of either family members and/or one or two hired people. There are also small and medium enterprises amongst the producers, although they are a minority. Given the high number of farmers and cooperatives, production and marketing is very atomised. As well, with almost 400 export companies, the supply chain is very dynamic, with many actors and interactions which lead to a complex network of relationships and product movement. Actual governance of these shareholders is mainly by "shared participant-governed networks" using the classification by Proven and Kenis ${ }^{[14]}$. Figure 2 below illustrates the functions of Almeria's farmers and cooperatives in the various stages of the supply chain.

\begin{tabular}{|c|c|c|c|}
\hline $\begin{array}{l}13,500 \text { Member } \\
\text { Family Farmer - } \\
\text { Greenhouse } \\
\text { Owner }\end{array}$ & \multicolumn{2}{|c|}{80 Marketing Cooperatives } & $\begin{array}{l}400 \text { export } \\
\text { companies- } \\
\text { National and } \\
\text { International }\end{array}$ \\
\hline $\begin{array}{l}\text { Phase 1: } \\
\text { Production }\end{array}$ & $\begin{array}{l}\text { Phase 2: } \\
\text { Logistics }\end{array}$ & Phase 3: Commercial & Markets \\
\hline Planting & Packaging & Commercialisation Sales & \\
\hline Cultivation & Warehouse & Planning & \\
\hline Harvest & Transport & Standardisation & \\
\hline
\end{tabular}

Figure 2 Almeria cooperative model according to function (first level cooperatives)

Figure 3 illustrates a traditional generic supply chain, where the transfer of goods and knowledge is sequential, as is the concept of traceability. However, if we look at the actual supply relationships (Figure 4), using Almeria horticultural production as an example, we can see that the system is far more complex, presenting organisational challenges for coordination and development and maintenance of traceability systems. This Almeria horticultural model can be used as an example of a resilient and flexible production system based on small farms, offering a good alternative for endogenous rural development.

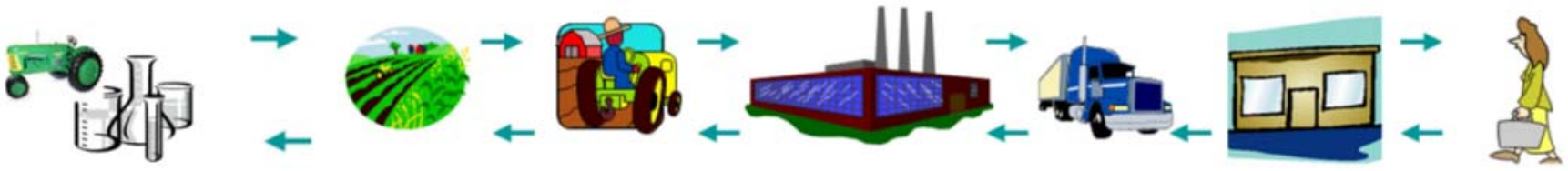

Figure 3 Traditional supply chain focused on sequential transfer of information

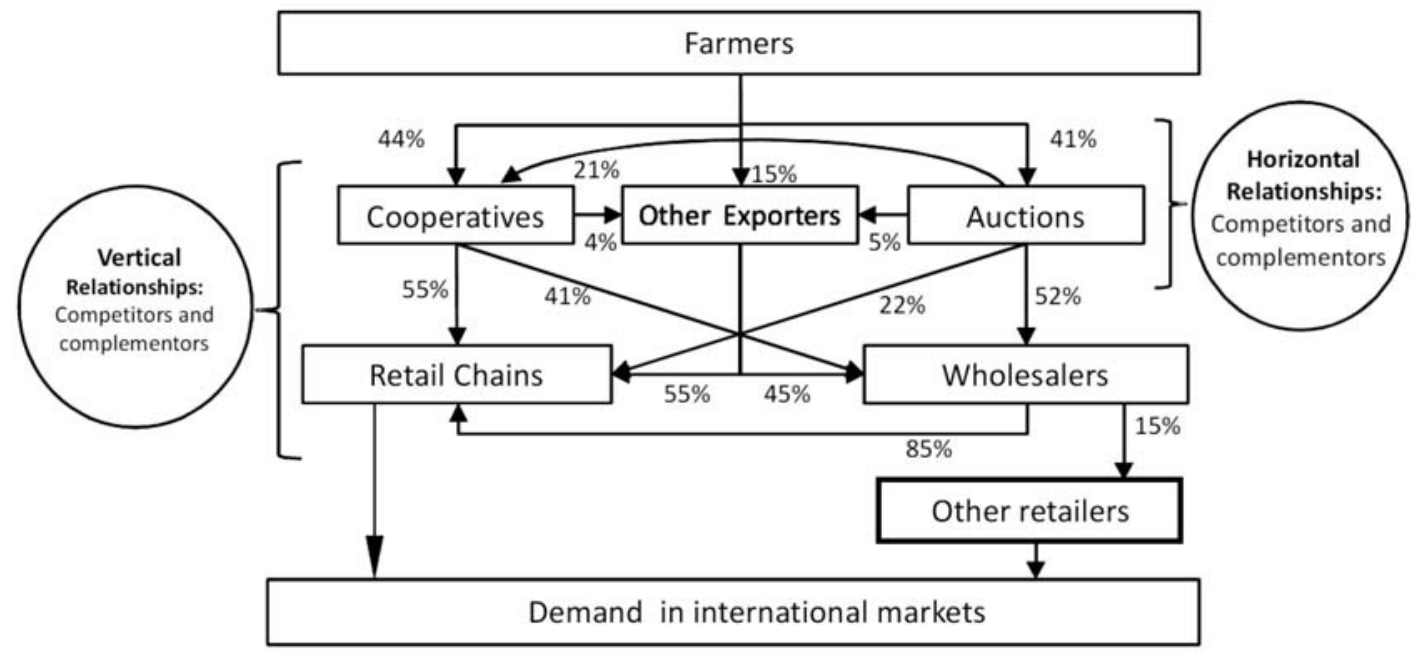

Note: \% refers to average trade. (Source: [15])

Figure 4 Basic relationships of vegetable exporters in Almeria, southeast Spain in the international supply chain 
As illustrated in Figure 4 above, it is important to not only consider supplier-buyer transactions, but also how actors of the same type interact in economic relationships. As a result, a sequential analysis is ill equipped to shed light on relationships, transactions and added value, since it focuses only on vertical transactions. Both vertical and horizontal relationships are relevant and therefore it is necessary to look at transactions and relations that are grouped $\therefore$ and also reciprocal $\therefore$, as in Figure 5.

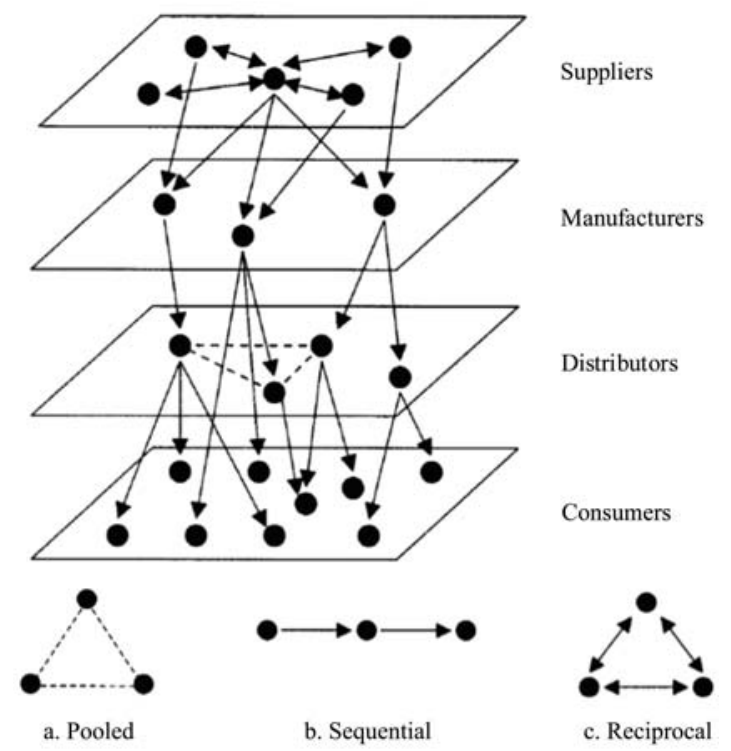

Figure 5 Net-chain structure and types of relationships (from Lazzarini, et al. ${ }^{[25]}$ )

Much work has been done on the economics of networks ${ }^{[16-18]}$. Networks can be economic or social or both, as is the case of cooperatives. Cooperatives can be considered a network structure, as they are member owned, member controlled, and for member benefit. They include market-like mechanisms, such as individual ownership and market incentives, with hierarchy-like instruments (e.g., administrative controls, authority and common staff in a central structure). They are a class of social and economic organisations which are unique and characterised by different coordination, control and incentive mechanisms, i.e., governance structures ${ }^{[19,20]}$.

\section{Network formation and organisational, effect on traceability}

Prior to developing new, more powerful traceability systems based on the new available technologies such as IoT and Big Data, it is necessary to understand how complex systems are interrelated between these technologies and actual traceability systems structures, so as to provide a base for further development through evolution of the existing systems.

\subsection{Network organisation}

Cooperative organisations develop networks, in order to reduce transaction costs, to facilitate knowledge transfer and exchange of resources, and be competitive. Cooperatives gain significant advantages if they are organized as networks ${ }^{[21]}$. Research in social networks demonstrated that network forms allowed businesses to acquire knowledge, gain legitimacy, and improve economic performance ${ }^{[22]}$. Sociologists base network formations on trust, cooperation, and reciprocity. Another school of transaction cost economists focus on network governance, looking at the combined effects of opportunism and imperfect or limited knowledge. In the transaction cost framework, networks are not considered unique organisational forms, but rather a diverse collection of relationships ${ }^{[23]}$. Networks are created to adapt to changes in social and economic environments. Williamson argues that in order to safeguard exchanges, support adaptation, and coordinate transactions, networks rely on "three pillars": pooling of resources (for example joint investments), coordination through contracts, and combinations of competition and cooperation ${ }^{[21,24]}$.

The criticism of network analysis is that while it can take into account social arrangements and knowledge transfer between firms; it doesn't pay attention to vertical ties: that is, market relationships-which influence greatly $\mathrm{R}+\mathrm{D}$ knowledge sharing and transference, creation and adoption of innovation, and, in the subject at hand, traceability systems and technologies. While networks and market analysis is useful, another approach entails the study of "net-chains". Net-chains are a combination of networks and sequential supply chains. Lazzarini et al. ${ }^{[25]}$ define a "net-chain" as a "set of networks comprised of horizontal ties between firms within a particular industry or group, which are sequentially arranged based on vertical ties between firms in different layers." Figure 6 below illustrates the concept of net-chain, along with the types of relationships: pooled, sequential and reciprocal.

The different layers represent the stages of the 
chain-supply (as shown in Figure 6), the different types of relationships represent how the different agents (as cooperatives, packaging companies, certification bodies, retailers) are interrelated. For example, there is a sequential relation between the producers, the classification and packaging companies (Figure 6, (1)), the transporter and the retailers. We can find a pooled relationship when some group individual transporters receive the orders of transport and organize optimal routes (Figure 6, (2)). We have a reciprocal relation between some producers, which have agreement to support them when the demand cannot be fulfilled by just one cooperative (Figure 6, (3)) (or farmer in a lower level).
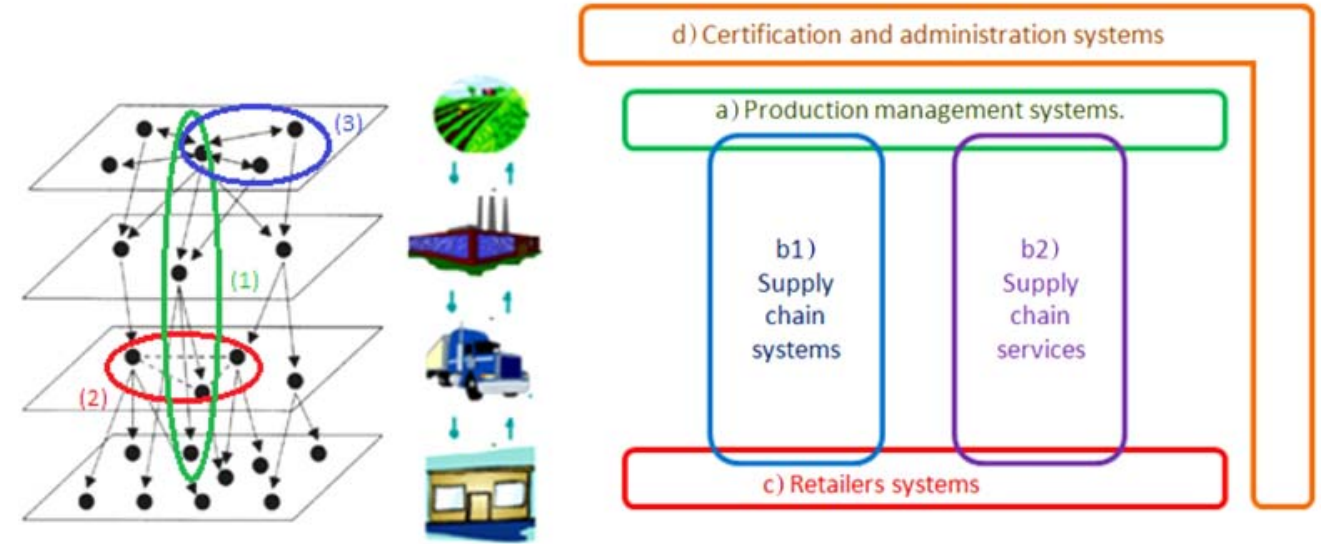

Figure 6 Traceability information systems in a complex Almeria type net-chain organisation

The net-chain perspective recognises the need to integrate the incentives and influences of markets, as well as the networks. Lazzarini et al. ${ }^{[25]}$ point out that market competition is crucial in defining knowledge networks, such as strategic alliances, platforms or joint ventures, in order to improve the competitive position of partners. Market incentives are seen to influence the formation of relationships and the share of technological information, for example in the case where market incentives exist which would lower the cost of production, increase product quality, or encourage innovation. Traceability technology and certification schemes are examples of such quality and innovation, requiring coordination in both horizontal and vertical dimensions of the net-chains.

Net-chain analysis merges supply chain and network perspectives of collaboration between businesses and organisation, emphasising value creation and coordination, which in turn are related to the type of relationships (pooled, sequential or reciprocal). Lazzarini et al. ${ }^{[25]}$ argue that taking into account these simultaneous relationships results in a more advanced understanding of complex inter-organisational relations, and ultimately, methods of adding value. Agricultural cooperatives play a key role in the formation and coordination of food net-chains ${ }^{[26]}$. An example can be found in a study of co-opetition in Almeria ${ }^{[15]}$, in which the vertical and horizontal relationships between a population of 107 agricultural cooperative businesses were examined, finding collaboration on $\mathrm{R} \& \mathrm{D}+\mathrm{I}$, technology creation and transfer, as well as promotion and quality of products.

\subsection{Net-chains and traceability}

In the case of Almeria, it was found that competitive advantages derive from co-opetition; essentially a net-chain generator of capabilities for internationalisation of small firms and their ability to export. Implicit in such capabilities is the compliance with traceability and quality standards, as well as collaboration in $\mathrm{R} \& \mathrm{D}+\mathrm{i}$, logistics, applications for joint subsidies and scheduling of sales. Relationships within the net-chain of Almeria are not merely horizontal between farmers, technicians and cooperatives and R\&D+i centers. As well, vertical relationships with retailers (who have more market power than wholesalers) are a major driver of collaboration between cooperatives, not only in the coordination of distribution channels, but also with respect to access to information, technology and the adoption of technology and $\mathrm{R}+\mathrm{D}$ (innovation). Collaboration with buyers results in the adoption of quality programmes, suggesting that types of relationships influence the type of 
knowledge transfer (and coordination mechanisms to manage this knowledge transfer).

Net-chain analysis is important for understanding traceability systems, for example, to exchange safely and rapidly traceability information within the complex web of horizontal and vertical relationships. The analysis has the ability to capture not only market incentives and relationships, but also the social relationships that exist between actors in the supply chain and the local networks.

The implementation of the traceability systems in this complex production model, with high atomization, but competitive due to the co-opetition of the different agents of the net-chain, has some special characteristics as shown in Figure 6:

a) Most of the links at the same level of the supply chains use compatible software systems (as a matter of fact there are few competitive software products in the market, easing the exchange of information).

b) The vertical data exchange is offered by 1) specific modules offered to the intermediate agents (every company has its part of the data that are exchanged with vertically and horizontally), or 2) by a service company that manages the data at several levels offering services (instead of software) to the different level companies.

c) Due to actual concentration, main retailers hold their own traceability systems, requiring the exchange/download of the data from the supply chain.

d) The capacity of managing the data at the first levels (mainly production) of the supply chain have been propelled at the beginning by the administration, supporting the development of standards and training (through special agencies such as IFAPA, in the case of Almeria).

This is the current status of the traceability systems in the Almeria case, which can be extrapolated to other areas where complex systems of agents in the food-chain are linked. This is the starting point for a new generation of Traceability Systems using technologies such as IoTs and Big Data. In this case, deeper knowledge of these net-chains is necessary, requiring extending their integration in the value chain and its scope, including the final consumers able to get full information about the products they are consuming, and the conditions to manage the results of the big data analysis taking account of the Privacy rules to be implemented.

In Almeria, the main drivers for this evolution to a Smart Farming and Big Data for traceability ${ }^{[1]}$ are:

\section{Pull factors:}

a) The requirements of global food security (extreme for developed markets), pulling for the implementation of advanced traceability systems in order to offer better and more complete information, assuring the quality of the products and the sustainability of the production ${ }^{[27,28]}$.

b) The need to take better, more optimal decisions and improve management control for the whole net-chain, integrating the production system and the whole food supply chain ${ }^{[28,29]}$. In the case of Almeria, the management of natural resources such as water and soil and the correct planning of the production is especially relevant.

\section{Push factors:}

c) The existence of specific technological developments $^{[27]}$ performed mainly by local tech companies (such as the Almeria based Hispatec, an agri-tech provider with more of $80 \%$ of the actual traceability system installations) and the research groups linked to the local Cooperative Bank (Cajamar), the associations of producer organisation (COEXPHAL) and the University of Almeria. All the agents are integrated in a strong industrial cluster or ecosystem linked to the local agriculture ${ }^{[30]}$.

d) The experience of applying technological solutions during the last 30 years by the farmers, that are already aware of the importance of the technology in a wide sense (management of water, reduction of the use of pesticides, integrated production, quality certification and traceability, use of renewable energy and reduction of the ecological footprint).

\subsection{Traceability system in Almeria}

With respect to the implementation of Big Data for traceability in the Almeria case $(\mathrm{F} \& \mathrm{~V})$ and Spain (olive oil). Two Trials Studies are underway, led by the University of Almeria (vegetables), with the participation of COEXPHAL and Cajamar experimental farm (Las 
Palmerillas), and in olive oil, with the collaboration of Hispatec, as part of the project "IoF2020 - Internet of Food \& Farm” and supported by Horizon2020 European Program. These study cases have as objective the use of the Big Data technologies using the European Platform FIWARE GEs ${ }^{[1]}$. The main objective is transferring the production and supply chain data to the platform in order to apply Big Data technologies for a new advanced traceability and a new generation of food security system.

Since 2005, Almeria has adopted Integrated Production (IP), an agricultural system of production of plant products, which fully utilizes all the natural resources and natural mechanisms of production assuring a long-term sustainable agriculture. It uses rationally different control methods as 1) biological control organisms, 2) permitted chemicals and 3) other cultural techniques, bringing into line the demands of the society, protection of environment and agricultural productivity. It takes account as well, of all the operations for handling, packaging, processing and labelling. It requires the use of the ICTs in order to manage all the required information the huge quantities of data generated (for traceability and quality management). The authors with the cooperation with companies from the sector to develop a traceability system (Figure 7). Nearly all the farmers, cooperatives and enterprises use these systems, and compared with traditional systems, there are several strengths: 1) Control of the origin of agricultural product quality safety, such as disease and pest forecast; 2) Including recent ICT, such as IoT and Big Data; 3) Based on the intelligent organizing cooperatives to improve the precision and effects of traceability.

The cooperative sector in Almeria Spain, has actively supported the farmers and cooperatives in traceability and certification compliance. The cooperative business model has aided the farmers in dealing with the challenges inherent in the implementation of traceability systems and innovations, much the same as it did with other transitions to free markets, integrated pest management, ICT systems, and other technological adoption and adaptations. Referring to the main challenges of food traceability identified in an extensive macro study by Bosana and Gebresenbet ${ }^{[9]}$, in Table 1 below, we can see the response of the Almeria cooperative sector.

Table 1 Main challenges of food traceability system and cooperative response

\begin{tabular}{|c|c|}
\hline Main challenges & Almeria cooperative response \\
\hline $\begin{array}{l}\text { 1.Regulatory and compliance } \\
\text { burdens }\end{array}$ & $\begin{array}{l}\text { Cooperatives and Association of Cooperatives notify, interpret and aid in traceability compliance for all members, as part of } \\
\text { the cooperative services. They also lobby and mediate on behalf of members, using their hierarchical administrative and } \\
\text { economic networks. }\end{array}$ \\
\hline 2. Safety and Quality & $\begin{array}{l}\text { Cooperatives function as systems of learning, with joint efforts to create and refine standardisation and refine a certain body } \\
\text { of knowledge. They also implement control systems for origin and quality, reducing fraud. Better coordination of supply } \\
\text { chain network, with increased efficiencies. Both vertical chains and horizontal networks. }\end{array}$ \\
\hline $\begin{array}{l}\text { 3.Social and reputational concerns } \\
\text { (consumer confidence, } \\
\text { health concerns, food crises) }\end{array}$ & $\begin{array}{l}\text { Cooperatives can emphasis traceability as an added value and can provide reputational (brand) credibility to individual } \\
\text { farmer members. Act as link between producers and consumers, with ability to provide feedback to food producers. } \\
\text { Ability to call for safety alerts and reduction in incidences and impacts of alerts as a result of capacity by virtue of } \\
\text { knowledge networks and control for detecting weak links. }\end{array}$ \\
\hline $\begin{array}{l}\text { 4.Economic and capital investment/ } \\
\text { economies of scale and market } \\
\text { power/volatility }\end{array}$ & $\begin{array}{l}\text { Cooperatives function to create economies of scale/increase market power and to reduce risk of individual members both } \\
\text { with respect to capital investment, and volatility. Increase access to markets which require certification and traceability } \\
\text { standard compliance. More equal and efficient allocation of costs of traceability systems. }\end{array}$ \\
\hline 5.Technology requirements & $\begin{array}{l}\text { Dissemination of scientific data and promotion of new technologies and data management for farmer members. Improved } \\
\text { tracking and tracing technologies. Standardization or compatibility of the system-interoperability }\end{array}$ \\
\hline $\begin{array}{l}\text { 7.Supply chain } \\
\text { management complexity }\end{array}$ & $\begin{array}{l}\text { Increase transparency as cooperatives are already embedded within complex systems. Reduced information asymmetries, } \\
\text { costs of inputs, transport, information and data management. Reduces administrative burdens and complexity for smaller } \\
\text { actors. }\end{array}$ \\
\hline
\end{tabular}

\subsection{Extension of the model to China}

In the case of China, it is possible to find a wide range of production models, from concentrated to highly distributed, including the existence of cooperatives, similar to Almeria, but showing an apparently lesser level of integration (the vertical relations dominating over the horizontal ones). This situation may have similarities to a previous stages noted in the case of Almeria. In this sense, it is possible to point the existence of plans by the administration similar to those pointed in push factor d) ${ }^{[21]}$. This is the case in some intensive production areas of Beijing and Shandong. 


\section{hispatec}

Production
ERPagro for the Supply Chain

Processing

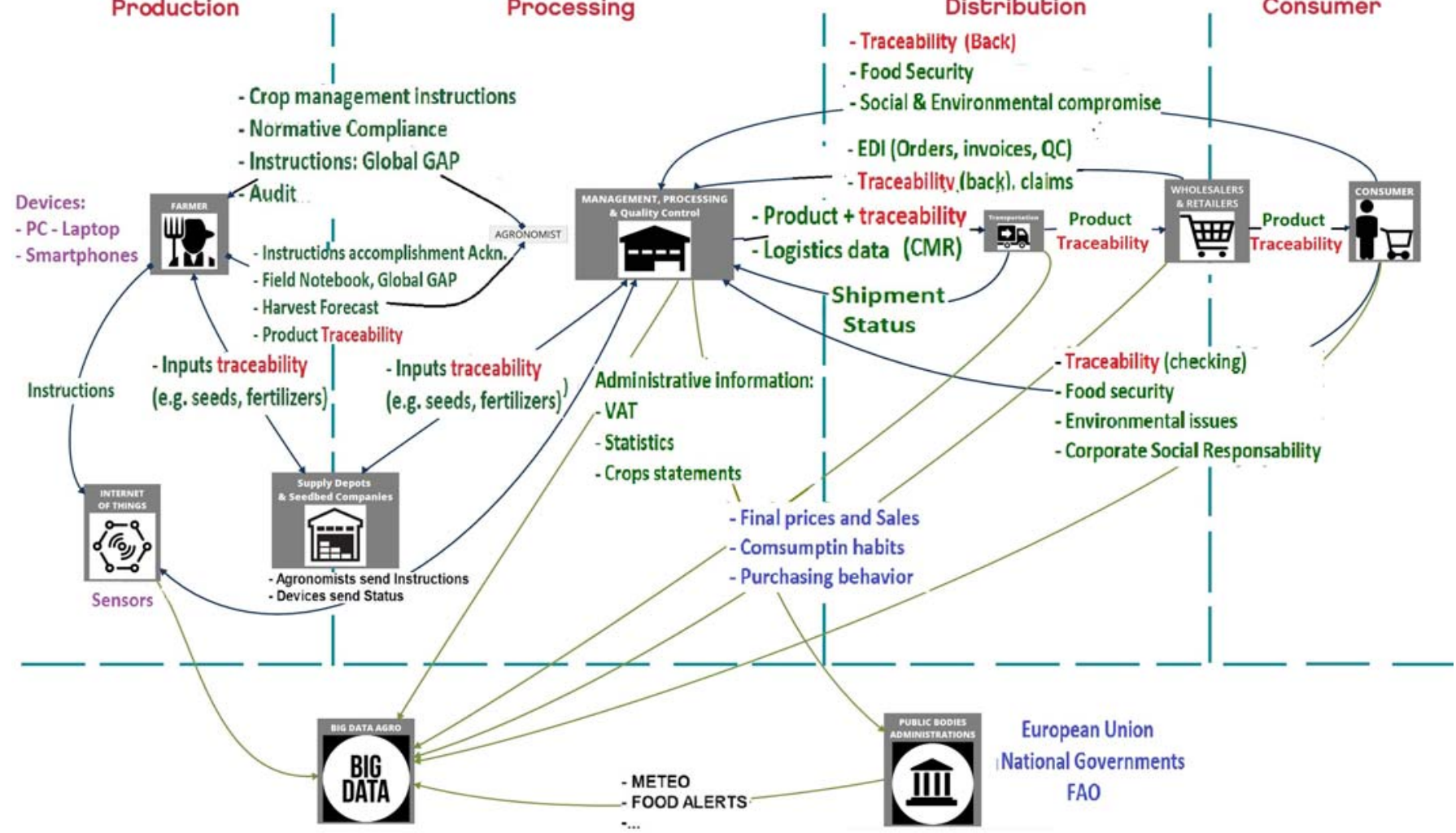

a. Input, flux and analysis of Traceability Data in Almeria between the different levels of the net-chain.

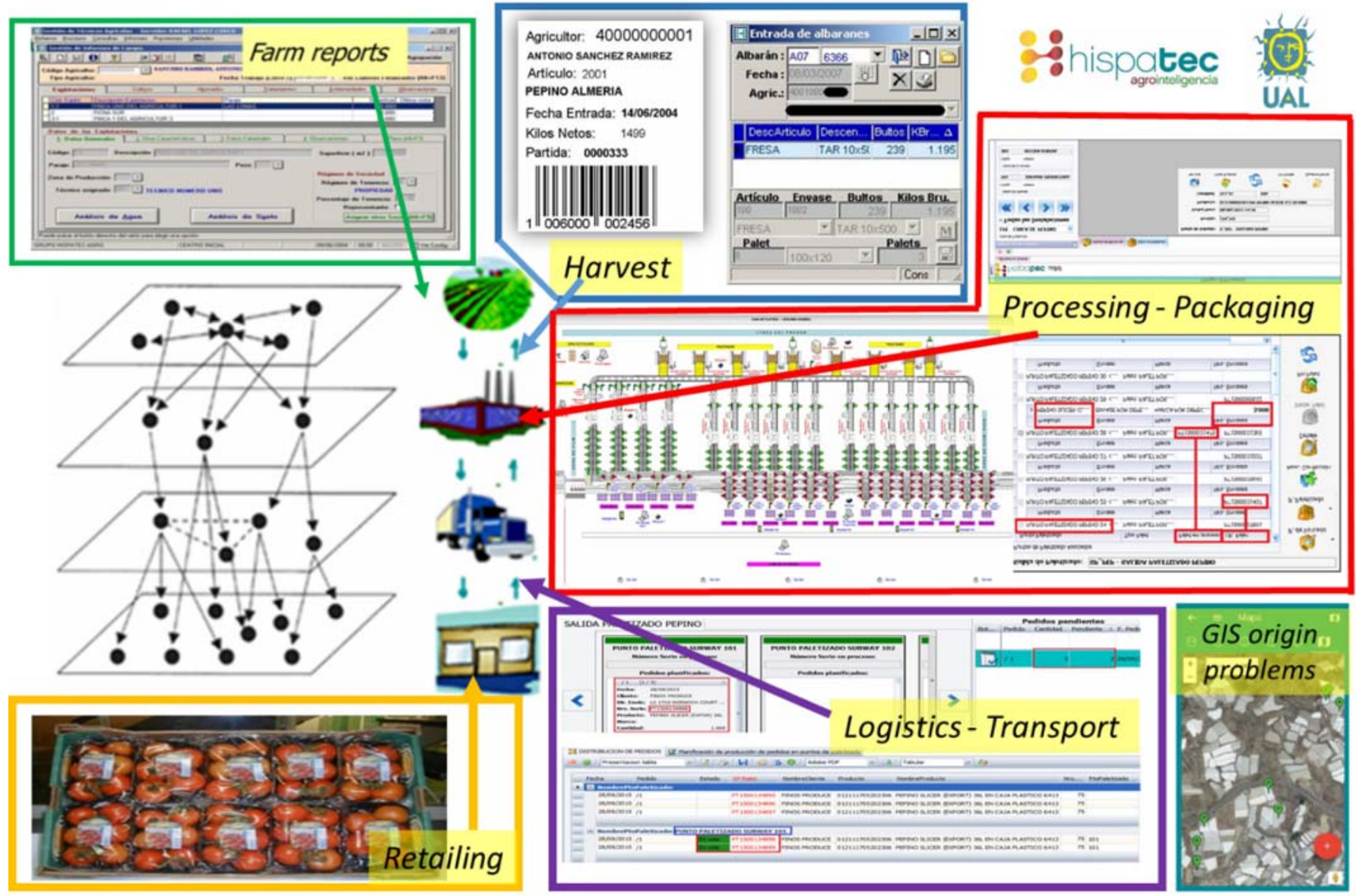

b. Traceability systems, some captures and processes examples

Figure 7 Traceability system in Almeria (ERP Agro) 
From the technological side, China is developing consistently new applications ${ }^{[32,33]}$, however, it has to deal with main weaknesses such as the application and uptake of these developments and a consistent understanding of the management network that it is extremely diverse. The example of Almeria could be used as a base study to maintain the co-operation of small agents in a way that supports a harmonic, social and economic development of the rural areas in China. This model of integrated co-operative small producers allows the rural population to reduce the income gap between urban and rural $\operatorname{areas}^{[34]}$. One example was a real-time agro-food authentication and supervision system on a novel code for improving traceability credibility ${ }^{[35]}$.

\section{Conclusions}

Cooperatives play an important role in high standard agricultural production and commercialization processes. Because they function as both social and economic networks, also creating both horizontal and vertical relationships, they function as an integral part of net-chains within complex food-supply chains. The diverse range of agents in these multiple relationships can be structured in net-chains (networks and supply chains), organized in two dimensions and three types of relationships. A consistent traceability system covering the whole supply-chain requires a consistent management of the traceability, including normalization, exchange and safety of the data and Big Data analysis and exploitation. We have analyzed how this integration has been reached in the case of Almeria for the actual traceability techniques, taking account of the complex net-chain or participating agents.

A clear model of the organisation at every level affords an effective management of the traceability data, and more effective and efficient adaptation to new conditions, whether normative or as a result of crisis events. By approaching complex supply chains and the inherent challenges of traceability systems, net-chain analysis is useful, particularly when coupled with organisational structures such as cooperatives, which inherently function as net-chains.

The Almeria model of cooperation and co-opetition, which is an example of socially distributed development, have been analysed in order to generate new generation traceability systems based on IoT and Big Data technologies. Future research includes deepening the understanding of the net-chains that should be extended in scope (including more agents as consumers) and space as an effect of globalization (scaling the size both vertical and horizontal of the dimensions of the supply chain to European and even global scales). The main objective is making possible a successful application of new technologies such as IoT and Big Data in the future traceability systems, maintaining the highly distributed economic model based on cooperatives.

This model is exportable to other areas suitable for the integration of small producers in similar net-chains, as it is the case of some areas of China, the study of this translation and adaptation if one of the next objectives in the actual works.

\section{Acknowledgments}

This research was funded by the Junta de Andalucía Project of Excellence P12-SEJ-2555 Challenges and Opportunities in the Concentration and Integration of Agrifood Companies; TEAP project included in the Marie Curie Actions (PIRSES-GA-2013-612659), the European Union Project entitled Internet of Food and Farm IoF2020 - H2020-IOT-2016, and Young Scientists Fund of National Natural Science Foundation of China (31401683).

\section{[References]}

[1] Wolfert S, Ge L, Verdouw C, Bogaardt M J. Big data in smart farming: A review. Agricultural Systems, 2014; 153: 69-80.

[2] Coase R H. The nature of the firm. Economica, New Series, 1937; 4 (16): 386-405.

[3] Osterwalder A, Pigneur Y. Business Model Generation: A Handbook for Visionaries, Game Changers, and Challengers. Wiley, 2010.

[4] Banhazi T M, Lehr H, Black J L, Crabtree H, Schofield P, Tscharke M, et al. Precision livestock farming: an international review of scientific and commercial aspects. Int J Agric \& Biol Eng, 2012; 5(3): 1-9.

[5] OECD. The Measurement of Scientific and Technological Activities. Oslo Manual: Guidelines for Collecting and Interpreting Innovation Data (Third Edition), OECD, Paris, 
2005; 164p.

[6] Fundación COTEC para la Innovación. Informe 2016, Madrid, Spain. (in Spanish).

[7] Lam A. The Oxford Handbook of Innovation, edited by Jan Fagerberg and David C. Mowery, Oxford, 2006.

[8] Regattieri A, Gamberi M, Manzini R. Traceability of food products: General framework and experimental evidence. Journal of Food Engineering, 2007; 8: 347-356.

[9] Bosona T, Gebresenbet G. Food traceability as an integral part of logistics management in food and agriculture supply chain. Food Control, 2013; 33: 32-48.

[10] Bijman J, van der Sangen G, Poppe K J, Doorneweert B. Support for Farmers' Cooperatives. Country Report the Netherlands, European Commission, Wageningen, 2012. https://ec.europa.eu/agriculture/sites/agriculture/files/external -studies/2012/support-farmers-coop/fulltext_en.pdf.

[11] RDI (Rural Development Institute). The role of cooperatives in community economic development. RDI Working Paper, 2005. Brandon, Manitoba, Canada: Brandon University.

[12] OSCAE. El cooperativismo agroalimentario Macromagnitudes del Cooperativismo Agroalimentario Español. Cooperativas Agroalimentarias, Madrid, Spain. http://www.agroalimentarias.coop/ficheros/doc/05375.pdf (in Spanish)

[13] La Voz de Almeria. Almeria tiene ya 398 empresas exportadoras hortofrutícolas. Report on presentation by the Regional Ministry of Agriculture and Fishing, Junta de Andalucía. 2017. http://www.lavozdealmeria.es/Noticias/ 124665/2/Almer\%C3\%ADa-tiene-ya-398-empresas-exportad oras-hortofrut\%C3\%ADcolas. (in Spanish)

[14] Provan K G, Kenis P. Modes of network governance: structure, management, and effectiveness. J. Public Adm. Res. Theory, 2008; 18: 229-252.

[15] Galdeano-Gómez E, Perez-Mesa J C, Giagnocavo C. Food exporters and co-opetition relationships: An analysis on the vegetable supply chain. British Food Journal, 2013; 117(5): 596-1609.

[16] Sanjeev G. Connections: An introduction to the economics of networks Princeton; Oxford, Princeton University Press, 2007; JSTOR.

[17] Galeotti A, Goyal S, Jackson M O, Vega-Redondo F, Yariv L. Network games, Rev Econ Stud, 2010; 77(1): 218-244.

[18] Ménard C. Hybrid Modes of Organisation. Alliances, Joint Ventures, Networks, and Other 'Strange' Animals. In Robert Gibbons and John Roberts (eds): the Handbook of Organisational Economics, Princeton University Press, 2012, pp.1066-1108.

[19] Chaddad F. Both markets and hierarchy: understanding the hybrid nature of cooperatives. International Workshop, Rural Cooperation in the 21st Century: Lessons from the Past, Pathways to the Future, Israel, June, 2009.
[20] Grandori A, Soda G. Inter-Firm Networks: Antecedents, Mechanisms and Forms. Organisation Studies, 1995; 16(2): 183-214.

[21] Karantininis K. The network form of the cooperative organisation. In Karantininis, K, Nilsson J. (Editors): Vertical Markets and Cooperative Hierarchies: the Role of Cooperatives in the Agri-food Industry, 2007; pp.19-34. Springer.

[22] Podolny J M, Page K L. Network forms of organisation. Annual Review of Sociology, 1998; 24(1): 57-76.

[23] Williamson O E. Comparative Economic Organisation: The Analysis of Discrete Structural Alternatives. Administrative Science Quarterly, 1991; 36: 269-296.

[24] Ménard C. Cooperatives: hierarchies or hybrids? Vertical markets and cooperative hierarchies: The Role of Cooperatives in the Agri-Food Industry, K. Karantininis and J. Nilsson (eds.), Dordrecht: Springer, 2007; pp.1-17.

[25] Lazzarini S, Chaddad F, Cook M. Integrating supply chain and network analyses: The study of netchains. Journal on Chain and Network Science, 2001; 1(1): 7-22.

[26] Iliopoulos C, Cook M, Chaddad F. Agricultural cooperatives in netchains. Journal on Chain and Network Science, 2016; 16(1): 1-6.

[27] Chen M, Mao S, Liu Y. Big Data: a survey. Mobile Network Appl, 2014, 19: 171-209.

[28] Poppe K J, Wolfert J, Verdouw C N, Renwick A. A European perspective on the economics of Big Data. Farm Policy Journal, 2015; 12: 11-19.

[29] Sonka S. Big Data and the Ag sector: more than lots of numbers. International Food and Agribusiness Management Review, 2014; 17(1): 1-20.

[30] Giagnocavo C. The Almeria agricultural cooperative model: creating successful economic and social communities. In the role of cooperatives in poverty eradication, 2012. UN Headquarters, New York, USA. https://social.un.org/ coopsyear/documents/AlmeriaPaperGiagnocavo.pdf

[31] Yu Y, Qin X, Zhang L. Development status of rural informatization in Beijing, China. Int J Agric \& Biol Eng, 2014; 4 (4): 59-65.

[32] Li X, Chen S, Guo L. Technological innovation of agricultural information service in the age of Big Data. J. Agric. Sci. Technol., 2014; 16: 10-15. (in Chinese)

[33] Liu D, Zhou J, Mo L. Applications of internet of things in food and agri-food areas. Transactions of the CSAM, 2012; 43: 146-152. (in Chinese)

[34] The Permanent Mission of the People's Republic of China to the UN (2012-06). China's National Report on Sustainable Development. http://www.china-un.org/eng/zt/sdreng/

[35] Yang X T, Qian J P, Li J, Ji Z T, Fan B L, Xing B, et al. A real-time agro-food authentication and supervision system on a novel code for improving traceability credibility. Food Control, 2016; 66: 17-26. 